\title{
Living-donor single-lobe lung transplant in a 6-year-old girl after 7-month mechanical ventilator support
}

\author{
Tsuyoshi Shoji, MD, Toru Bando, MD, Takuji Fujinaga, MD, and Hiroshi Date, MD, Kyoto, Japan
}

Living-donor single-lobe lung transplant was performed in a 6-year-old girl with post-Stevens-Johnson syndrome bronchiolitis obliterans who had been ventilator dependent for 7 months. To our knowledge, this case represents the longest reported preoperative mechanical ventilation period before living-donor single-lobe lung transplant.

\section{CLINICAL SUMMARY}

A 6-year-old girl had Stevens-Johnson syndrome diagnosed after receiving oral medication for an upper respiratory tract infection. She was treated with corticosteroids but required mechanical ventilation on July 7, 2007. Under intensive care, she was extubated on July 18, 2006. Although there was a gradual improvement in her skin lesions, her respiratory status worsened again, and a diagnosis of bronchiolitis obliterans was made. She was reintubated on November 13, 2007.

The patient was transferred to Kyoto University Hospital on May 21, 2008. On admission, she was receiving mechanical ventilation through a tracheostomy. The ventilator setting was synchronous intermittent mandatory ventilation mode with a frequency of 10 breaths/min, pressure control of $26 \mathrm{~cm} \mathrm{H}_{2} \mathrm{O}$, and pressure support of $26 \mathrm{~cm} \mathrm{H}_{2} \mathrm{O}$. Arterial blood gas measurement with this setting (inspired oxygen fraction 0.3) revealed a $\mathrm{pH}$ of 7.33 , arterial $\mathrm{Po}_{2}$ of 88.6 $\mathrm{mm} \mathrm{Hg}$, and arterial $\mathrm{PCO}_{2}$ of $62.3 \mathrm{~mm} \mathrm{Hg}$. the patient's spontaneous respiratory rate was 30 to 35 breaths/min, and her own respiratory effort was preserved.

Cadaveric lung transplant was not a realistic option, because in Japan brain death is accepted only for potential donors older than 15 years. The patient's mother, 35 years old, was the only available living donor in her family. The surgical options were discussed with the family, and they were willing to proceed with living-donor single-lobe lung transplant, which they understood to be still an experimental procedure. The respective heights and weights were $113 \mathrm{~cm}$ and $16.0 \mathrm{~kg}$ for the recipient and $160 \mathrm{~cm}$ and $58.0 \mathrm{~kg}$ for the donor. The estimated forced vital capacity of the graft

From the Department of Thoracic Surgery, Kyoto University, Kyoto, Japan.

Disclosures: None.

Received for publication April 1, 2009; accepted for publication April 11, 2009; available ahead of print June 17, 2009

Address for reprints: Tsuyoshi Shoji, MD, Department of Thoracic Surgery, Kyoto University, 54 Shogoin-Kawahara-cho, Sakyo-ku, Kyoto 606-8507, Japan

(E-mail: tshoji@kuhp.kyoto-u.ac.jp).

J Thorac Cardiovasc Surg 2010;139:e112-3

0022-5223/\$36.00

Copyright (c) 2010 by The American Association for Thoracic Surgery doi:10.1016/j.jtcvs.2009.04.015 (mother's right lower lobe) was $73.3 \%$ of the recipient's predicted forced vital capacity. Three-dimensional computed tomographic volumetric evaluation indicated the recipient's right chest cavity to be $825 \mathrm{~mL}$ and the donor's right lower lobe to be $1334 \mathrm{~mL}$.

On June 5, 2008, after mechanical ventilation for 7 months, the patient underwent living-donor single-lobe lung transplant with the donor's right lower lobe through a right anterolateral thoracotomy. After reventilation, the graft was clearly oversized macroscopically and was manually compressed into the chest cavity. Closure of the chest did not cause hemodynamic instability, however, and blood gas values were satisfactory. Chest radiography after the transplant revealed no obvious atelectasis in either lung.

The postoperative course was relatively uneventful. The patient was completely weaned from the ventilator on postoperative day 47. She was discharged from the hospital on postoperative day 81 . Chest radiography 6 months after transplant revealed good inflation of the right lung graft and satisfactory diaphragm movement (Figure 1). At that time, the patient's 6-minute walk distance was 380 meters, and her lowest oxygen saturation on room air was $95 \%$. Arterial blood gas measurement revealed a $\mathrm{pH}$ of 7.40 , arterial $\mathrm{Po}_{2}$ of $88.7 \mathrm{~mm} \mathrm{Hg}$, and arterial $\mathrm{PCO}_{2}$ of $33.9 \mathrm{~mm} \mathrm{Hg}$. Forced vital capacity was $1.08 \mathrm{~L}$ ( $75.1 \%$ predicted), and forced expiratory volume in 1 second was $0.72 \mathrm{~L}$. At followup 9 months after the transplant, that patient had returned to a normal life without oxygen inhalation and was able to perform daily activities.

\section{DISCUSSION}

It is well known that patients receiving mechanical ventilation at the time of lung transplant, whether cadaveric ${ }^{1}$ or livingdonor lobar, ${ }^{2}$ face an increased risk of operative death. This pediatric patient was dependent on a ventilator for 7 months, which we believe is the longest period before living-donor lobar lung transplant ever reported. Furthermore, she had only one available donor, and the donor lobe was clearly oversized. Shiraishi and colleages ${ }^{3}$ reported successful livingdonor single-lobe lung transplant in a 4-year-old boy who was receiving ventilatory support. His preoperative ventilator period was only 4 weeks, however, and his size mismatch $(118 \%)$ was not as great as in our case $(162 \%)$ according to 3-dimensional computed tomographic volumetric evaluation.

Disuse atrophy of the diaphragm caused by long-term mechanical ventilation was a marked concern. The oversized graft might have further jeopardized the diaphragm 

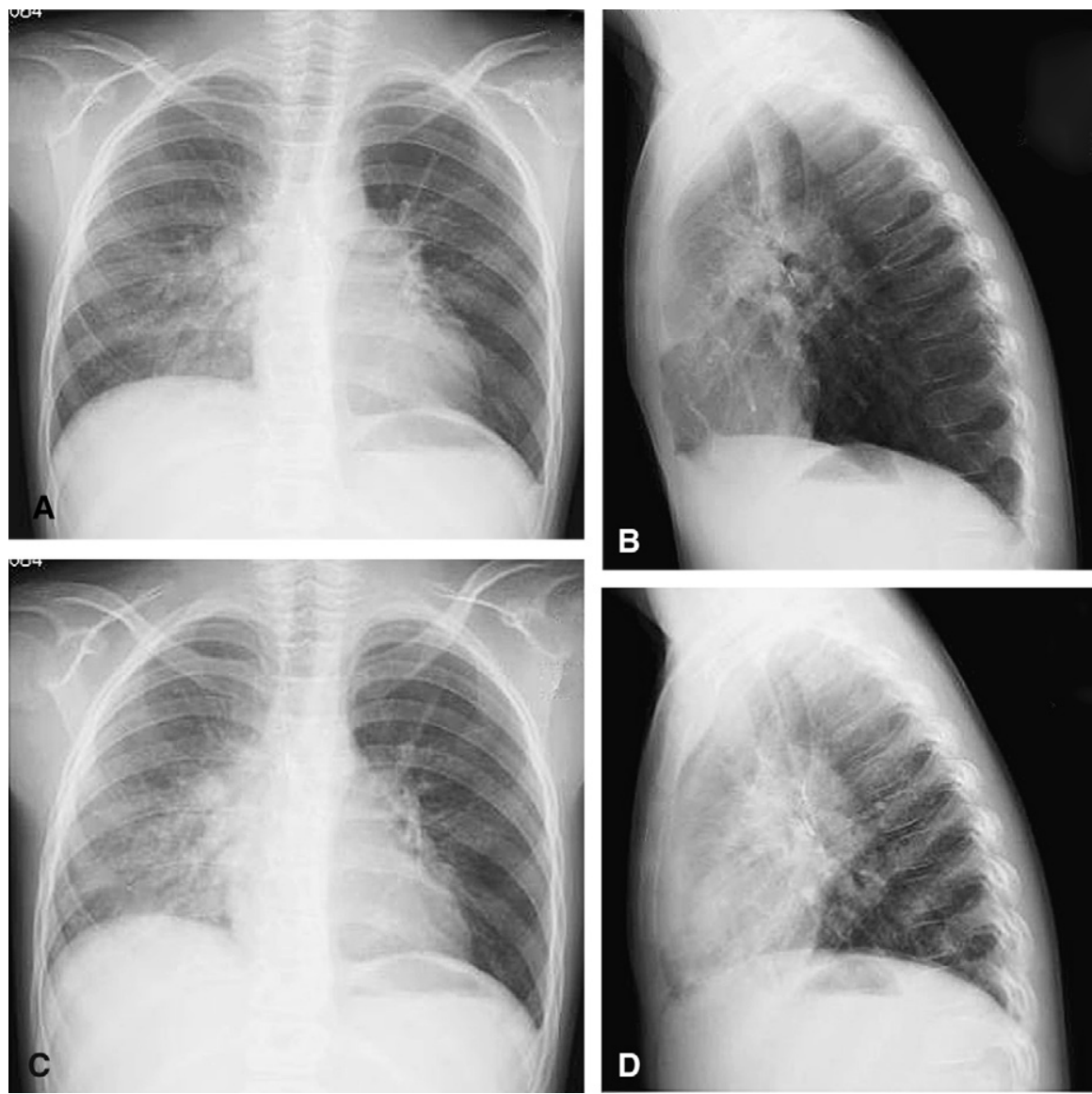

FIGURE 1. Chest radiograph 6 months after transplant in maximal inspiratory (A, frontal view; B, lateral view) and expiratory (C, frontal view; D, lateral view) states.

movement. Although it took 47 days, weaning from ventilator was successful, indicating that disuse atrophy of the diaphragm was minimal despite long-term ventilation. We emphasize that the patient's respiratory effort was well preserved preoperatively.

Most centers accept only very sick patients as candidates for living-donor lobar lung transplant. If the prospective recipient is too sick, however, placing healthy donors at risk is not justified. Our single-lobe lung transplant was performed as a lifesaving procedure. Although the short-term outcome was satisfactory, long-term fol- low-up is needed to assess whether this procedure is ultimately justified.

\section{References}

1. Christie JD, Edwards LB, Aurora P, Dobbels F, Kirk R, Rahmel AO, et al. Registry of the International Society for Heart and Lung Transplantation: twenty-fifth official adult lung and heart/lung transplantation report-2008. J Heart Lung Transplant. 2008;27:957-69.

2. Starnes VA, Bowdish ME, Woo MS, Barbers RG, Schenkel FA, Horn MV, et al. A decade of living lobar lung transplantation: recipient outcomes. J Thorac Cardiovasc Surg. 2004;127:114-22.

3. Shiraishi T, Hiratsuka M, Munakata M, Higuchi T, Makihata S, Yoshinaga Y, et al. Living-donor single-lobe lung transplantation for bronchiolitis obliterans in a 4-year-old boy. J Thorac Cardiovasc Surg. 2007;134:1092-3. 